\title{
ИЗОТОПНО - ГЕОХИМИЧЕСКАЯ СИСТЕМАТИКА НЕОАРХЕЙСКИХ СУБЩЕЛОЧНЫХ ПОРОД КЕЙВСКОЙ СТРУКТУРЫ
}

\section{Ветрин В.P.}

Геологический институт КНЦ РАН, Апатиты; ИМГРЭ, Москва, vetrin@geoksc.apatity.ru

Инициальный субщелочной магматизм Кейвской структуры проявлен в образовании вулкано-плутонической ассоциации латитов-монцонитов-гранитов, в состав которой входят породы известково-щелочного и субщелочного составов, относящиеся к производным субвулканической, гипабиссальной и мезоабиссальной фаций глубинности. U-Pb возраст циркона из пород ассоциации определен в $2674 \pm 6$ млн. лет (рис. 1) и отражает время кристаллизации пород [4].

Исследованные кварцевые латиты и кварцевые монцониты содержат 9.1-13.5 ppm Sm и 47.9-69.2 ppm Nd, что, соответственно, в 60-90 и 105-150 раз выше содержаний этих элементов в хондрите $\mathrm{C} 1$. Отношение ${ }^{147} \mathrm{Sm} /{ }^{144} \mathrm{Nd}$ составляет $0.11-0.12$ и соответствует его среднекоровому значению $(0.118 \pm 0.017)$. Величина измеренного отношения ${ }^{143} \mathrm{Nd} /{ }^{144} \mathrm{Nd}$ в породах определена в 0.511061-0.511365, и значения модельных возрастов расположены в узком возрастном интервале от 3.14 до 3.21 млрд. лет при $\varepsilon \mathrm{Nd}_{(2670)}$ от 2.2 до -1.3. Эти данные определяют мезоархейский возраст протолита, и участие в составе пород ассоциации как корового, так и мантийного вещества. В настоящее время в пределах Кейвского сегмента породы мезоархейского возраста достоверно не установлены, но их наличие можно предполагать в составе базитовой нижней коры или гранулитбазитового слоя, верхняя часть которого в пределах Кейвской структуры предполагается на глубинах более 3-4 км [7]. В пределах Балтийского щита породы с возрастами 3.2- 3.6 млрд. лет выявлены в различных частях Карельской провинции $[12,13,9,10]$, а также в северо-западной части Кольской провинции [8].

На диаграммах в координатах ${ }^{147} \mathrm{Sm} /{ }^{144} \mathrm{Nd}-{ }^{143} \mathrm{Nd} /{ }^{144} \mathrm{Nd}$ минералы и вмещающие их породы характеризуются изохронными зависимостями с возрастами в $1817 \pm 72$ и $1510 \pm 51$ млн. лет. (рис. 2). Полученные датировки существенно меньше возраста пород, определенного U-Pb методом по циркону, и в пределах ошибок определения близки к значениям возраста протерозойского метаморфизма и метасоматоза, проявленных в пределах Кейвского сегмента (1.95-1.5 млрд. лет, [3, 4]) и рас-

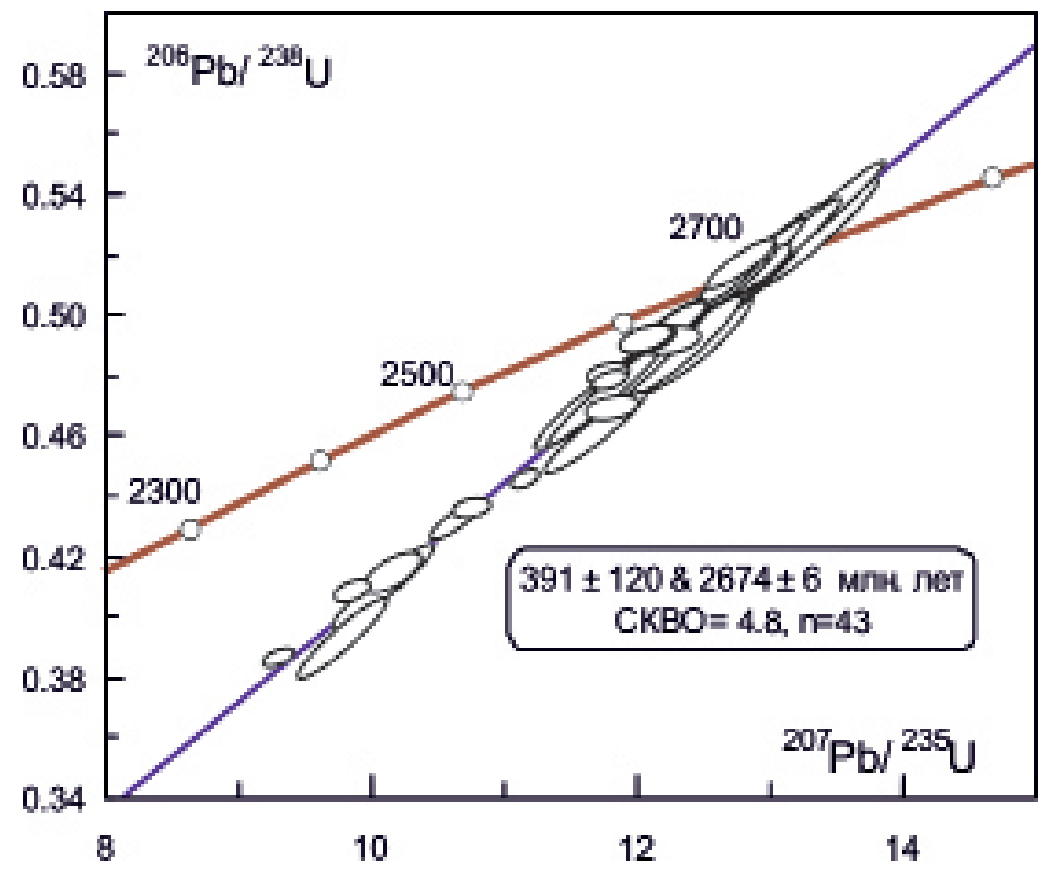

Рис. 1. Диаграмма с конкордией в координатах ${ }^{207} \mathrm{~Pb} /{ }^{235} \mathrm{U}-{ }^{206} \mathrm{~Pb} /{ }^{238} \mathrm{U}$ для циркона из пород ассоциации латитов-монцонитов-гранитов. Определения выполнены на ионном микрозонде SHRIMP-II

(ВСЕГЕИ, г. Санкт- Петербурге). 

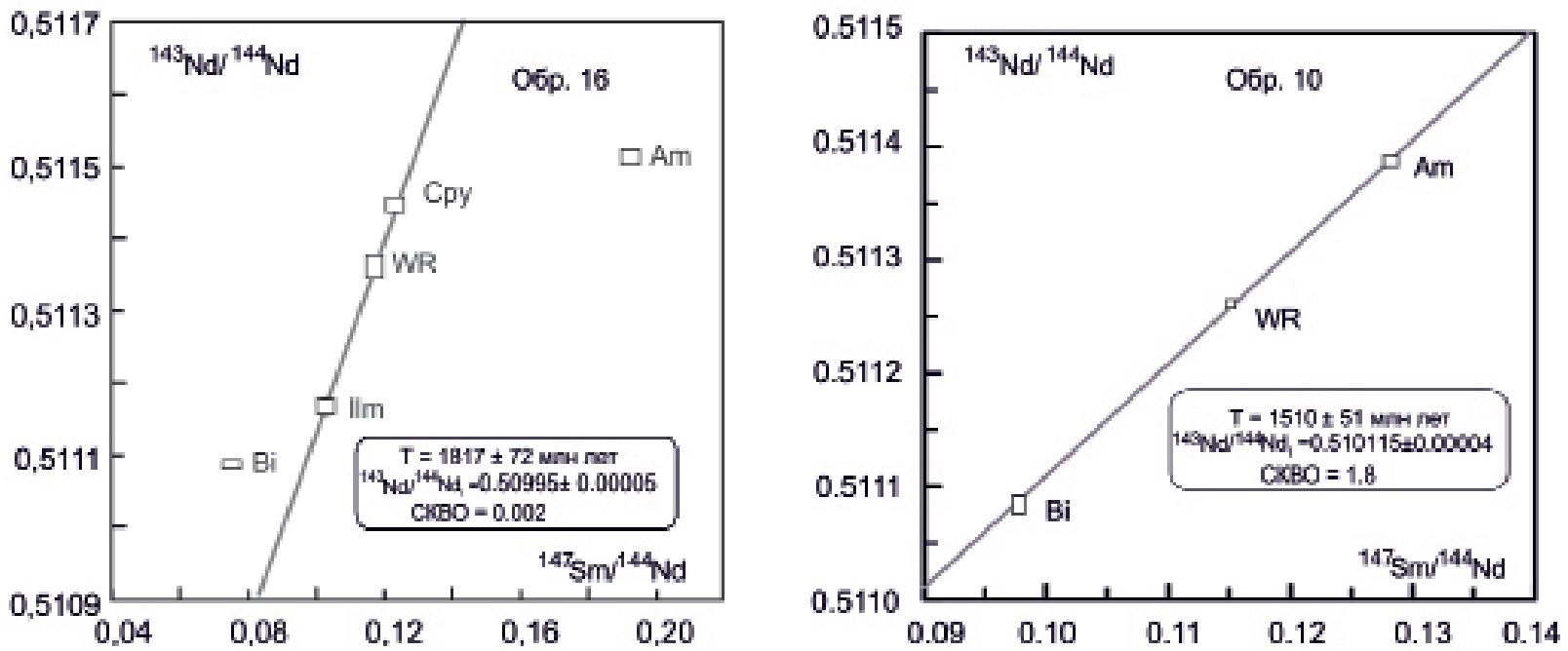

Рис. 2. Диаграммы в координатах ${ }^{147} \mathrm{Sm}-{ }^{144} \mathrm{Nd}-{ }^{143} \mathrm{Nd} /{ }^{144} \mathrm{Nd}$ для образцов кварцевого монцонита (№ 16) и кварцевого латита (№ 10). WR- порода, СРу- клинопироксен, Am- амфибол, Ilm- ильменит, Ві- биотит. Измерения концентраций $\mathrm{Sm}, \mathrm{Nd}$ и изотопного состава $\mathrm{Nd}$ выполнены на масс-спектрометре TRITON TI фирмы ThermoFinnigan MАТ в ЦИИ ВСЕГЕИ (г. Санкт-Петербург).

положенной к югу структуры Имандра-Варзуга [1]. Обычно предполагается неизменность отношения $\mathrm{Sm} / \mathrm{Nd}$ во время внутрикорового плавления, метаморфизма, эрозии и переотложения материала [14], что обусловлено сходством геохимических свойств $\mathrm{Sm}$ и $\mathrm{Nd}$. Величина отношения $\mathrm{Sm} / \mathrm{Nd}$ в изученных породах колеблется незначительно (0.18-0.19), и наличие изохронных зависимостей со снижением цифр определяемого возраста было обусловлено, вероятно, перераспределением изотопов $\mathrm{Sm}$ и $\mathrm{Nd}$ между древними и новообразованными минералами породы в процессе протерозойского метаморфизма.

Lu-Hf изотопная система изучена в цирконе из образцов кварцевого латита и кварцевого монцонита. Двухстадийный модельный возраст циркона $\mathrm{T}_{\mathrm{Hf}}(\mathrm{DM})$ из этих пород составляет 3.05-3.39 млрд. лет, и близок возрасту $\mathrm{T}_{\mathrm{Nd}}(\mathrm{DM})$ вмещающих пород, что обусловлено, вероятно, сингенетичностью породы и циркона. Этот вывод подтверждается расположением точек состава циркона в области TA (Terrestrial Array [15]), определяющей когерентность Sm-Nd и Lu-Hf изотопных систем рассматриваемых пород и циркона в процессе магматической дифференциации (рис. 3a). Начальные отношения ${ }^{176} \mathrm{Hf} /{ }^{177} \mathrm{Hf}$ находятся в пределах $0.280950-0.281069$, и точки состава циркона образуют поле в районе тренда эволюции однородного хондритового резервуара (CHUR). Изученные кристаллы циркона располагаются в полях составов этого минерала из гнейсов Кольской сверхглубокой скважины, эклогитов южной части Кольского полуострова и главным образом в поле составов неоархейских кристаллов циркона из ксенолитов гранатовых гранулитов нижней коры.

Для всех рассматриваемых пород предполагается базитовый состав протолитов $[5,6,11]$. По величине $\varepsilon \mathrm{Hf}(\mathrm{T})$ точки состава циркона локализованы в области развития коры с ${ }^{176} \mathrm{Lu} /{ }^{177} \mathrm{Hf}=0.015$ и возрастами в 3.0-3.3 млрд. лет (рис. 3, б). Это свидетельствует, вероятно, об образовании исходных расплавов преимущественно за счет вещества с длительным временем нахождения в коре. Породы ассоциации латитов- монцонитов-гранитов содержат повышенные концентрации крупноионных литофильных элементов ( $\mathrm{K}, \mathrm{Cs}, \mathrm{Rb})$, Р3Э и деплетированы относительно $\mathrm{Nb}, \mathrm{Ta}$, Ti, что наряду с преобладающими отрицательными значениями $\varepsilon \mathrm{Nd}(\mathrm{T})$ в породе и $\varepsilon \mathrm{Hf}(\mathrm{T})$ в цирконе также свидетельствует о происхождении исходных магм главным образом за счет плавления пород коры. В то же время присутствие мантийного компонента в породах ассоциации определяется положительными значениями $\varepsilon \mathrm{Nd}(\mathrm{T})$ и $\varepsilon \mathrm{Hf}(\mathrm{T})$ в части образцов пород и кристаллов циркона.

Гранитоиды ассоциации пространственно совмещены с неоархейскими породами основного состава. Догранитные тела основных пород образуют рои даек и два крупных массива- Щучьеозерский и Цагинский, сложенные дифференцированным комплексом пород от габбро, габброноритов 


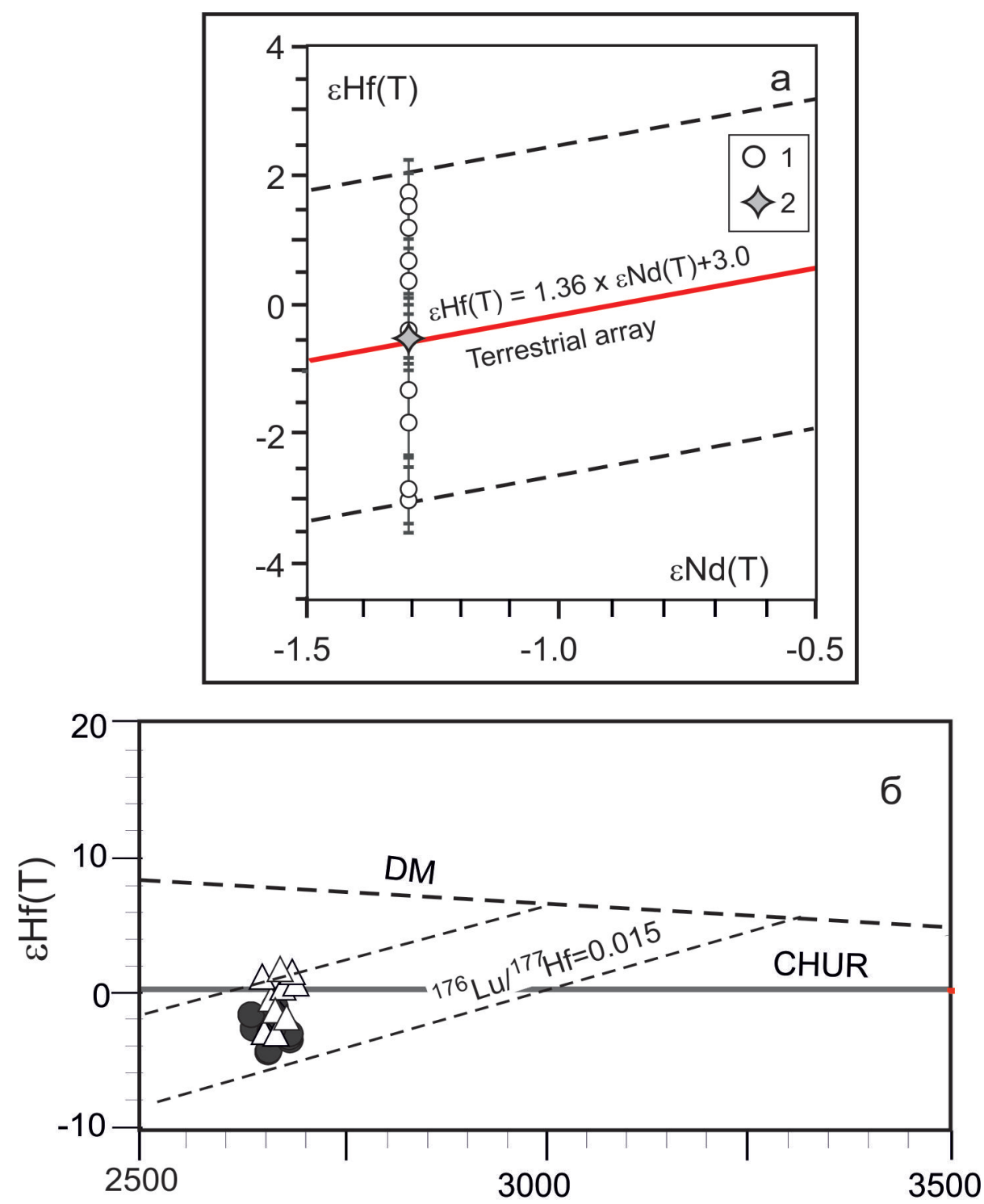

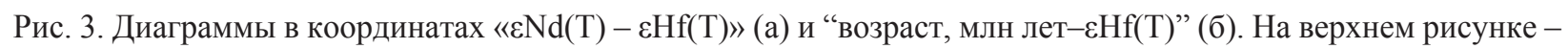
обр.17- кварцевый монцонит (частные значения и среднее). На нижнем рисунке пунктиром показаны тренды эволюции коры с возрастами 3.0-3.3 млрд. лет при ${ }^{176} \mathrm{Lu} /{ }^{177} \mathrm{Hf}=0.015$. Залитые кружки- обр. 8 (кв. латит), треугольники- обр. 17- (кв. монцонит). Изотопный состав Нf в цирконе из датированных на SHRIMP II кристаллах определен в Университете Маквари, Сидней, Австралия методом MC-LA-ICP-MS.

в краевых частях тел до лейкогаббро, лабрадоритов и габбролабрадоритов в их центральных частях. Жильные тела монцонитов, порфировидных амфибол-биотитовых и эгирин-арфведсонитовых гранитов пересекают породы массивов, и в пределах ошибок определения U- Рb методом имеют близкое с ними время образования. Гранитоиды не входят в состав дифференцированного комплекса массивов основных пород, и пространственная совмещенность близких по составу пород кремнекислого и основного составов позволяет рассматривать последние лишь в качестве источников тепла, необходимого для плавления коры и возникновения кремнекислых расплавов. Последние наряду с «коровыми» изотопными характеристиками в ряде случаев имеют повышенные концентрации радиогенных изотопов $\mathrm{Nd}$ и $\mathrm{Hf}$, унаследованные, вероятно, от расплавов основного состава, вызывавших плавление пород коры.

Как было показано выше, результаты изучения Lu-Hf изотопной системы пород ассоциации латитов-монцонитов-гранитов не противоречат базитовому составу их протолитов, подвергавшихся щелочному метасоматозу, происходившему до внедрения интрузий габбролабрадоритов и ще- 
лочных гранитов [2]. Это позволяет предполагать образование исходных магм ассоциации латитов- монцонитов- гранитов за счет плавления метасоматически измененных пород основного состава нижней коры при внедрении в нее базитовых расплавов, исходных для пород дайкового комплекса и массивов габбролабрадоритов.

Исследования выполнены при поддержке РФФИ (гранты 17-35-50002, 16-05-00026а), и госконтракта № 13/17-1.

\section{Литература}

1. Балашов Ю.А. Геохронология раннепротерозойских пород Печенгско- Варзугской структуры Кольского полуострова // Петрология. 1996. Т. 4. № 1. С. 3-25.

2. Белолипецкий А.П., Гаскельберг В.Г., Гаскельберг Л.А., Антонюк Е.С., Ильин Ю.И. Геология и геохимия метаморфических коплексов раннего докембрия Кольского полуострова. Л.: Наука. 1980. 240 c.

3. Баянова Т.Б. Возраст реперных геологических комплексов Кольского региона и длительность процессов магматизма. СПб: Наука. 2004. 174 с.

4. Ветрин В.Р., Родионов Н.В. Геология и геохронология неоархейского анорогенного магматизма Кейвской структуры, Кольский полуостров // Петрология. 2009. Т. 17. № 6. С. 578-600.

5. Ветрин В.Р., Белоусова Е.А., Чупин В.П. Редкие элементы и Lu-Hf изотопная систематика циркона из плагиогнейсов Кольской сверхглубокой скважины: вещество палеоархейской коры в мезоархейских метавулканитах // Геохимия. 2016. №1. С. 105-125.

6. Ветрин В.Р., Белоусова Е.А., Кременецкий A.A. Lu- Hf изотопная систематика циркона из ксенолитов нижней коры Беломорского подвижного пояса // Записки PMO. 2017. Ч. CXLVI. № 3. С. 1-16.

7. Литвиненко И.В., Анкудинов С.А., Платоненкова Л.Н., Сипарова Ю.А. Глубинный разрез Кейвской синклинорной зоны. Геология и глубинное строение восточной части Балтийского щита. Л.: Наука. 1968. C. 104-110.

8. Guitreau M., Blichert-Toft J., Martin H., Mojzsis S.J., Albarede F. Hafnium isotope evidence from Archean granitic rocks for deep-mantle origin of continental crust. Earth Planet Sci. Lett. 2012. V. 337-338. P. 211-223.

9. Hölttä P., Heilimo E., Huhma H., Kontinen A., Mertanen S., Mikkola P., Paavola J., Peltonen P., Semprich J., Slabunov A., Sorjonen-Ward P. The Archaean of the Karelia Province in Finland. Geol. Surv. Finland. Spec. Paper. 2012. V. 54. P. 21-72.

10. Kröner A., Compston W. Archaean tonalitic gneiss of Finnish Lapland revisited: zircon ion-microprobe ages. Contrib. Mineral., Petrol. 1990. V. 104. P. 348-352.

11. Mints M.V., Glaznev V.N., Konilov A.N., Kunina N.M., Nikitichev A.P., A.B. Rajevski, Sedikh Yu.N., Stupak V.M., Fonarev V.I. Early Precambrian of the Northeast of Baltic Shield: paleogeodinamica, structure and evolution of continental crust. M.: Nauchny Mir. 1996. 287 p. (In Russian)

12. Mutanen T., Huhma H. The 3.5 Ga Siurua trondhjemite gneiss in the Archaean Pudasjärvi Granulite Belt, northern Finland // Bull. Geol. Soc. Finland. 2003. V. 75. P. 51-68.

13. Sergeev S.A., Bibikova E.V., Matukov D.I., Lobach-Zhuchenko S.B. Age of the magmatic and metamorphic processes in the Vodlozero Complex, Baltic Shield: an ion microprobe (SHRIMP II) U-Th-Pb isotopic study of zircons. Geochemistry Intern. 2007. V. 45. P. 198-205.

14. Taylor S.R., McLennan S.M. The Continental Crust: its Composition and Evolution. 1985. Oxford: Blackwell Scientific Publications. 312p.

15. Vervoort J.D., Blichert-Toft J. Evolution of depleted mantle: Hf evidence from juvenile rocks through time. Geochim., Cosmochim. Acta. 1999. V. 63. N. 3/4. P. 533-556. 